Document downloaded from:

http://hdl.handle.net/10251/61560

This paper must be cited as:

Serrano, A.; Espinach, FX.; Julian, F.; Rey Tormos, RMD.; Mendez, JA.; Mutje, P. (2013). Estimation of the interfacial shears strength, orientation factor and mean equivalent intrinsic tensile strength in old newspaper fiber/polypropylene composites. Composites Part B: Engineering. 50:232-238. doi:10.1016/j.compositesb.2013.02.018.

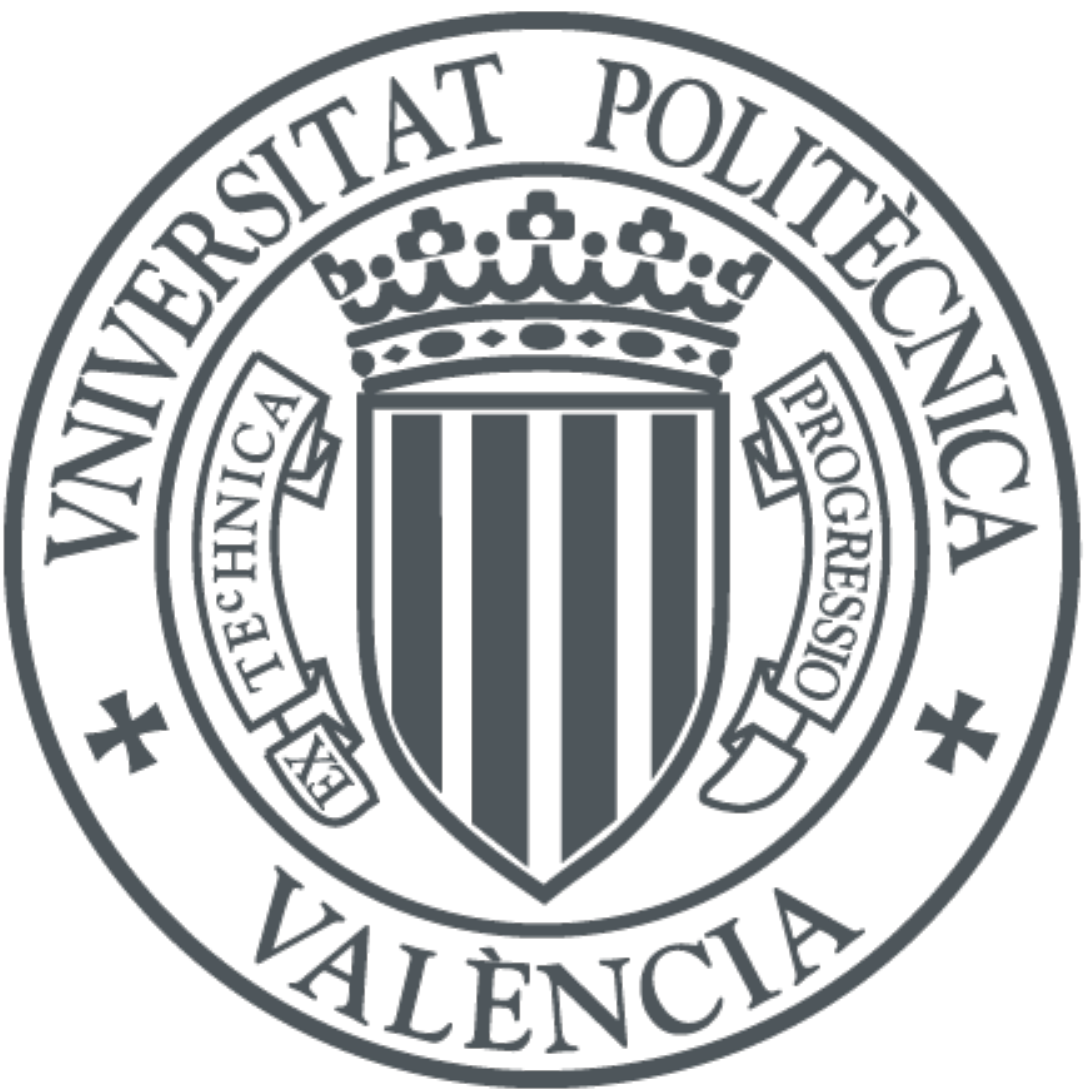

The final publication is available at

http://dx.doi.org/10.1016/j.compositesb.2013.02.018

Copyright Elsevier

Additional Information 


\title{
Estimation of the interfacial shears strength, orientation factor and mean equivalent intrinsic tensile strength in old newspaper fiber / polypropylene composites.
}

\author{
Serrano, $A^{b}$., Espinach, F.X. ${ }^{*}$., Julian, $F^{a}$., del Rey, $R^{c}$., Mendez, J.A ${ }^{b}$., Mutje, $P^{b}$. \\ "Escola Politecnica Superior. Avda. Lluis Santalo, s/n, 17071 Girona, Spain. \\ Francisco.espinach@udg.edu, TIf. +34 972418 920, FAX +34 972418399
}

aDesign, Development and Product Innovation, Dpt. Of Organization, Business Management and Product Design, (Spain).

${ }^{b}$ Laboratory of Paper Engineering and Polymer Materials, Dpt. Of Chemical Engineering, University of Girona (Spain)

'Instituto para la Gestión Integrada de las Zonas Costeras. IGIC. Escola Politècnica Superior de Gandia.Universitat Politècnica de València (Spain)

\section{Abstract}

The present paper investigates the suitability of old newspapers (ONP) as a source of reinforcing fibers for composite materials. Different percentages of ONP fibers were compounded with polypropylene (PP). A coupling agent was added to the compound to improve the interface between matrix and reinforcing fibers. Tensile test were performed to obtain the mechanical properties of the composite materials. Micromechanics of the fibers were obtained using Hirsch model, Bowyer-Bader methodology and Kelly-Tyson equations. Due to the presence of a percentage of calcium carbonate in the obtained fibers $(10 \%)$, the computed intrinsic characteristics were addressed as equivalent. The most important results were the mean equivalent intrinsic tensile strength of the ONP fibers, the mean orientation 
angle and the mean interfacial shear strength. The contributions of the matrix, the subcritical and the supercritical fibers to the tensile strength of the composite material were also computed.

Keywords: A: Fibres. B: Mechanical properties, Interface. C: Micro-mechanics.

\section{Introduction}

Due to environmental awareness, interest in natural fibers as an alternative to glass fibers as reinforcement in polymer composites has grown and generates a great deal of interest [1]. Advantages of natural fibers in composites are high availability, biodegradability, low cost, low density...

Currently the most used matrixes for natural fiber composites are thermoplastics, and the most common for this purpose are polypropylene, polyethylene and poly-vinyl chloride.

Lignocellulosic materials can be classified in three categories depending on its behavior inside the polymeric matrix [2]. The flours from wood and other low cost flours from agroforestry can be considered as particulate fillers that are able to increase the elastic moduli of the composite materials but have little influence on its strength. The virgin wood fibers and the cellulosic fibers from recycled papers had a higher aspect ratio (length by diameter ratio), and when are used as reinforcement with the adequate coupling agents, are able to increase both, the elastic moduli and the strength of the composite materials. The improvement of the elastic moduli is slightly superior to that obtained with particulate fillers [3-9]. The natural strands as jute, kenaf, flax, are the most effective cellulosic reinforcement fibers [2, 10-15].

A major problem which restricts reinforcing effect during the incorporation of lignocellulosic fibers into polymeric matrixes is the incompatibility between the hydrophilic fibers and the hydrophobic polymers. This fact normally results in poor interfacial adhesion and in restricted ability of stress transfer from the matrix to the reinforcement. Therefore, the enhancement of 
compatibility between the hydrophobic thermoplastic polymer and the hydrophilic natural fibers has attracted much attention of the researchers, and various techniques were evaluated in previous works [15-18]. Generally speaking, chemical modifications are used to decrease the polarity of the fibers surface in order increase its compatibility with the polymer surface. The treatments with short chain hydrophobic agents such as acetyls, isocyanates, or sylanes have proved insufficient to optimize the mechanical properties of the composite materials [19]. Actually, coupling agents, which react with the fiber's hydroxyl groups, but additionally are able to interlock with matrix chains are the best treatment to increase the mechanical properties of the composite. In this respect, the use of an interfacial coupling agent, such as Maleated polyolephines is the most commonly used method to improve the fiber-matrix interface, by means of $-\mathrm{OH} /$ maleic chemical interactions $[16,20]$. More specifically the use of maleated polypropylene (MAPP) has yielded good tensile properties of the composites [9, 21]. In addition, an increase of the available -OH groups at fiber surface by $\mathrm{NaOH}$ treatment might enhance the reactivity at interface level [13], resulting in improvements of the mechanical properties of the natural fiber composites.

The literature, on the application of newspaper recycled lignocellulosic fibers as reinforcement of polyolefinic thermoplastic matrixes, recognizes that it constitutes a valuable source of fiber $[22,23]$. In spite of their advantages, the use of cellulose fibers from newspaper as reinforcement elements for thermoplastics has not been extensively investigated [1]. Some possible reasons include their limited thermal stability during processing, poor dispersion in the thermoplastic melt, and limited compatibility with the matrix, which contribute to unsatisfactory final properties of the composites [1]. Many years ago newspaper contained mostly mechanical pulp form softwood (pine, spruce, poplar) and inorganic fillers as mineral fillers, ink and process aid material [24]. Nowadays the mechanical pulp from soft wood has been replaced by a mixture of recycled paper and mechanical pulp, mostly from hardwood (poplar, beech...). 
In injection molded composites the orientation factor $\left(\chi_{1}\right)$ and the interfacial shear strength $(\tau)$ are key factors for the competitiveness of the product. Specifically, $\chi_{1}$ is an empirical factor that accounts for fiber orientation and has a value of unity for aligned fibers, $3 / 8$ for planar random configurations and 1/5 for three-dimensional random orientation. Nonetheless it is difficult to determine this factor for injection molded fiber-polymer systems [23]. The analysis of $\chi_{1}$ and $\tau$ by means Bowyer-Bader methodology and the estimation of $\sigma_{t}{ }^{F}$ by means of Kelly-Tyson modified equation [25] proved to be valid to study micromechanics of composite materials [26-31].

The objective of this work is to evaluate the orientation factor $\left(\chi_{1}\right)$, the interfacial shear strength $(\tau)$ and the equivalent intrinsic tensile strength of the ONP fibers $\left(\sigma_{t}{ }^{F}\right)$ inside the PP matrix. The MAPP content was optimized to $6 \mathrm{wt} \%$ preparing composite materials with a $40 \%$ of ONP and 0 to $8 w t \%$ of MAPP. Composite materials with 20 to 50 wt $\%$ of ONP fibers content, with a 6 wt $\%$ of MAPP, were formulated, compounded and tested. Hirsch model was used to obtain the intrinsic Young's moduli of the fibers, Bowyer-Bader methodology to compute the orientation factor $\left(X_{1}\right)$ and the interface shear strength $(\tau)$, and the Kelly-Tyson modified equation to calculate the equivalent intrinsic tensile strength $\left(\sigma_{t}{ }^{F}\right)$.

\section{Materials and methods}

\subsection{Materials}

The old newspaper, containing $85 \%$ of thermomechanical pulp from hardwood and $15 \%$ of calcium carbonate mineral filler, was supplied by Punt Diari, edited by Rotimprès (Spain).

The composites were prepared using homopolymer polypropylene (PP) (Isplen PP090 G2M) that was provided by Repsol -YPF (Tarragona, Spain) as the polymer matrix. Polypropylene functionalized with maleic anhydride (MAH-PP) (Epolene G3015) was acquired from Eastman Chemical Products (Spain) and used as coupling agent. Diethyleneglycol dimethyl ether (diglyme) was supplied by Clariant and was used as dispersing agent. 
Decahydronaphthalene (decalin) supplied by Fisher Scientific was used to dissolve the PP matrix in the fiber extraction from composites process. Figure 1 shows the chart flow we followed.

\section{Figure 1}

\subsection{Disintegration of the old newspaper}

Old newspaper was submitted to the disintegration process by means of a pilot scale pulper (Pucel Cell from Metrotech, France) equipped with an helicoidal rotor, deflectors, and with an effective volume of $20 \mathrm{l}$. The disintegration was performed at $20 \mathrm{rev} / \mathrm{s}$ rotor speed, at a temperature of $50^{\circ} \mathrm{C}$, and $10 \%$ consistency. The initial newspapers were cut into pieces of $10 \times 10 \mathrm{~cm}$, approximately and were soaked in water with a $1 \%$ of $\mathrm{NaOH}$ before starting the rotor. Afterwards the pulped material was filtered and oven dried at $80^{\circ} \mathrm{C}$. Following ONP fibers were dispersed in a water-diglyme (1:3) mixture. The use of diglyme in the previous step limits the formation of hydrogen bonds between the cellulosic fibers [29] . A $5 \%$ of the $\mathrm{CaCO}_{3}$ was lost during the disintegration and individualization processes.

\subsection{Composites compounding}

Composite materials comprising 20 , to $50 \mathrm{wt} \%$ PP/ONP fibers, were obtained. The materials were prepared in a Brabender ${ }^{\circledR}$ plastograph internal mixing machine. The working parameters were $80 \mathrm{rpm}$ during $10 \mathrm{~min}$ at a temperature of $180^{\circ} \mathrm{C}$. The resulting blends were grounded with a knives mill, dried and stored at $80^{\circ} \mathrm{C}$ for at least $24 \mathrm{~h}$ before processing. Composite materials with 40 wt $\%$ of ONF fibers and 0 to $8 \%$ of MAPP were similarly obtained.

\subsection{Composite processing}

The samples for the tensile test were produced with a steel mould in an injection-molding machine (Meteor 40, Mateu\&Solé). Ten test specimens, of each obtained composite blend, 
were used for the experiment. Standard composite specimen samples (approx. $160 \times 13.3 \times 3.2 \mathrm{~mm}$ ) were obtained and used to measure the tensile properties in agreement with ASTM D638 [26, 28].

\subsection{Mechanical characterization}

Prior to the mechanical test the specimens were stored in a Dycometal conditioning chamber at $23^{\circ} \mathrm{C}$ and $50 \%$ relative humidity during $48 \mathrm{~h}$, in agreement with ASTM D638. Results were obtained from the average of at least 5 samples [26, 28].

\subsection{Fiber extraction from composites}

Reinforcing fibers were extracted from composites by matrix solubization using a Soxhlet apparatus and decalin as solvent. Once the fibers were extracted, they were rinsed with acetone followed by distilled water in order to remove the solvent residue. Finally the fibers were dried in an oven at $105^{\circ} \mathrm{C}$ for 24 hours.

\subsection{Determination of the fiber length and diameter}

Fiber's length distribution and diameter of the extracted ONP fibers were characterized by means of a Kajanni analyzer (FS-300). A diluted aqueous suspension of fibers was analyzed during 2 to 5 minutes, and the length of the fibers was evaluated considering an amount of individual fibers in the range of 2500 to 3000 units.

\subsection{Determination of the Young's modulus of the fiber $\left(E_{t}^{F}\right)$}

The intrinsic tensile modulus of the triticale straws was determined using the Hirsch model $[28-30,32]$. 


\subsection{Determination of the interfacial shear strength $(\tau)$ and the fiber orientation factor $\left(\chi_{1}\right)$ and the intrinsic tensile strength of the fiber $\left(\sigma_{t}{ }^{F}\right)$}

With current standard processing techniques, perfect fiber alignment is almost impossible, and the orientation factor $\left(\chi_{1}\right)$ must be taken into account. The calculation of $\tau$ can be accomplished through the Kelly-Tyson modified equation (Eq. 1) [25, 33].

$$
\sigma_{t}^{C}=\chi_{1}\left(\sum_{i}\left[\frac{\tau \cdot l_{i}^{F} \cdot V_{i}^{F}}{d^{F}}\right]+\sum_{j}\left[\sigma_{t}^{F} \cdot V_{j}^{F}\left(1-\frac{\sigma_{t}^{F} \cdot d^{F}}{4 \cdot \tau \cdot l_{j}^{F}}\right)\right]\right)+\left(1-V^{F}\right) \cdot \sigma_{t}^{m *}
$$

To solve the Kelly-Tyson modified equation it is necessary to know or estimate the values of $E_{t}^{F}, E_{t}^{m}$, and the characteristics of the reinforcing fibers: intrinsic strength $\left(\sigma_{t}^{F}\right)$, orientation factor $\left(\chi_{1}\right)$, interfacial shear strength $(\tau)$, fiber diameter $\left(d^{F}\right)$, and length $\left(l^{F}\right)$. By previous extraction from the polymeric matrix, the fiber distribution can be empirically obtained. However, usually $\sigma_{t}^{F}, \chi_{1}$ and $\tau$ are unknown.

In order to solve the equation, a Bowyer-Bader methodology was used [28, 29, 34] to evaluate $\chi_{1}$ and $\tau$ [27].

\section{Results and discussion}

\subsection{Composite Tensile properties}

As mentioned above fibers contained $15 \%$ calcium carbonate, which in the process of disintegration lost $5 \%$. Thus, the added reinforcement to the composite material was made up of $10 \%$ of $\mathrm{CaCO}_{3}$ and $90 \%$ of ONP fibers.

The tensile strength of a composite is a combination of the properties of the matrix and the reinforcement and the ability of its interface to transfer shear strengths $[30,33]$. Lignocellulosic fibers combined with hydrophobic thermoplastics as polypropylene (PP) needed to be modified because effective wetting of the fibers and strong interfacial adhesion 
were required in order to achieve higher mechanical properties of the composite [23, 35-37]. To optimize the interface ONP fibers/PP different percentages of MAPP were tested. Figure 2 shows the behavior the $40 \%$ ONP fibers composite materials tensile strength. As it can be observed the strength of the composite increased quickly with the percentage of MAPP until the $4 w t \%$. For the 4 to $8 w t \%$ of MAPP the strength was almost constant with a local optimum value at $6 w t \%$ of MAPP. The decrease on the tensile strength at the higher coupling agent content is attributed to self-entanglement among the coupling agent chains, rather than with the polymer, resulting in slippage [20].

Figure 2

It was found that, for the currently tested formulations, the addition of $6 \mathrm{wt} \%$ of MAPP allowed the ONP fibers to develop the maximum reinforcing effect into the composite.

Above we introduced the fact that the reinforcement was not $100 \%$ pure ONP fiber. Vallejos et al [38] researched composites with a $40 \%$ of $\mathrm{CaCO}_{3}$ and a $60 \%$ of $\mathrm{PP}$, with a tensile strength of $30 \mathrm{Mpa}$ and a Young's modulus of $2.3 \mathrm{GPa}$. The equivalent content of a $40 \%$ ONP fibers composite was to be $4 \%$ of $\mathrm{CaCO}_{3}, 36 \%$ of ONP fibers and $60 \%$ of PP. Taking in account that the tensile strength of the PP was found to be 27.6 Mpa and the additive character of the rule of mixtures, the equivalent tensile strength of a $4 \% \mathrm{CaCO}_{3}, 96 \% \mathrm{PP}$ composite material had to be $27.84 \mathrm{Mpa}$, and the equivalent contribution of the $\mathrm{CaCO}_{3}, 0.24$ Mpa. Similarly if the Young's modulus of the PP was found to be $1.5 \mathrm{GPa}$ and consequently the equivalent Young's modulus for the same composite had to be $1.58 \mathrm{GPa}$, and the equivalent contribution of the $\mathrm{CaCO} 3$ was $0.08 \mathrm{GPa}$.

Once established the $6 w t \%$ of MAPP we studied the influence of ONP fibers content. The tensile properties of the ONP fiber-PP composites were influenced by the percentage of ONP fibers, as shown in table 1. The tensile strength and the Young's moduli of the PPMAPP composites increased linearly with the ONP fibers content from 20 to $50 \mathrm{wt} \%$. 
Meanwhile the tensile elongation at break of the composites decreased linearly from $4.1 \%$ to $2.2 \%$ when the ONP fibers content was increased from 20 to $50 \mathrm{wt} \%$.

\section{Table 1}

\subsection{Orientation factor and interfacial shear strength}

The intrinsic tensile strength of reinforcing ONP fibers inside the PP composite is function of its intrinsic properties but also of its degree of adhesion with the polymer matrix and the mean orientation of the fibers inside the matrix. Fig. 3 shows the stress-strain curves for the tested reinforcement percentages, from 20 to $50 \mathrm{wt} \%$, and for the PP matrix, reflecting the change of the $\sigma_{t}{ }^{C}$ in relation with the deformation $\varepsilon_{t}{ }^{C}$. The curves correspond with the experimental outcome that was closed to the mean $\sigma_{t}^{C}$ value. It was verified that $\sigma_{t}^{C}$ increased when $\varepsilon_{t}{ }^{C}$ decreased, as a consequence of the rise in rigidity of the material. The composite shows a typical tensile stress-strain curve for a treated fiber composite.

The theoretical equivalent intrinsic Young's modulus of the ONP fibers, using Hirsch model, was evaluated to be $21.2 \mathrm{GPa}$ as a mean value, close to the $18.2 \pm 1.1$ for stone groundwood fibers found by Lopez et al [28]. $E_{t}^{c}$ for the 20 to 50 wt\% of ONP fibers composites were 2.87, 3.83, 4.18, and 5.31GPa respectively.

\section{Figure 3}

The preparation of the composites and its injection resulted in a reduction of the fiber lengths $[26,27]$. The diminution of the fiber lengths could be caused by the attrition happening during the composite fabrication $[39,40]$. This is more relevant for coupled composites as the fiber is better tied to the matrix [28]. Hence it was necessary to obtain the length distribution of the fibers inside the composite (fig 4). It was observed that the average length of the fibers inside the composite decreased with the wt\% of ONP fibers. The weighted fiber length experienced a substantial reduction when the percentage of reinforcement evolved from 20 to $50 \mathrm{wt} \%$ (table 1). This is consistent with the results of other investigations [26, 
28]. At the same time the diameter of the strands was considered approximately constant and independents of the wt\%, with a mean value of $21.6 \mu \mathrm{m}$. Consequently the aspect ratio $\left(\mathrm{I}^{\mathrm{F}} / \mathrm{d}^{\mathrm{F}}\right)$ diminished at the same time as the wt\% increased.

\section{Figure 4}

The next step was the evaluation of $\chi_{1}$ and $\tau$. The experimental data values required to apply Bowyer-Bader methodology are summarized in table 2.

\section{Table 2}

Strain levels at $1 / 3$ and $2 / 3$ of the breaking point were chosen as reference levels to perform the calculations. The values of the stress at levels 1 and 2 were obtained from the experimental data.

Table 3 shows the obtained results after Bowyer-Bader methodology and Kelly-Tyson equations were applied.

\section{Table 3}

The mean value of the orientation factor $\left(\chi_{1}\right)$ for the different composites (20 to $50 \mathrm{wt} \%$ ) was 0.346. The obtained orientation factor implied a mean orientation angle of $39.9^{\circ}$, taking in account that $\chi_{1}=\cos ^{4} \theta$ [41]. The angle is similar to the one obtained by Lopez et al. [28] with a mean orientation angle of $43^{\circ}$ for stone groundwood and Vallejos et al. [26] with a mean orientation angle of $43^{\circ}$ for hemp strands.

The critical fiber length $\left(l_{c}^{F}\right)$ was calculated from $\mathrm{I}_{c}{ }^{\mathrm{F}}=\left(\mathrm{d}^{\mathrm{F}} \cdot \sigma_{\mathrm{t}}{ }^{\mathrm{C}}\right) / 2 \tau[27]$.

The obtained value of the mean interfacial shear strength $(\tau)$ was $14.57 \mathrm{MPa}$. The value stands in the interval of $15.95 \mathrm{MPa}$ and $13.8 \mathrm{MPa}$, derived from the application of the Von Misses and Tresca criteria respectively $[30,42]$, considering the $\sigma_{t}^{m}$ of the polypropylene. Consequently the result seems reasonable. 


\subsection{Mean equivalent intrinsic tensile strength of ONP fibers}

When we used the Kelly-Tyson equation we do not contemplated the inclusion of fillers. Therefore, we perform calculations assuming that $100 \%$ of the reinforcing was ONP fiber. Although the contribution of the $\mathrm{CaCO}_{3}$ was residual the result could not be considered as the intrinsic strength of the fibers, and consequently we referred to the intrinsic properties of the fibers as equivalent.

Once obtained the values for $\chi_{1}$ and $\tau$ we used Kelly-Tyson modified equation (Eq. 1) to obtain a value of the equivalent $\sigma_{t}^{F}$ for all the tested composites (Table 3). The mean value of the equivalent $\sigma_{t}^{F}$ for 20 to $50 \mathrm{wt} \%$ composites was found to be $514.3 \pm 34.7 \mathrm{MPa}$.

\subsection{MAPP influence on $\tau, \chi_{1}$ and $\sigma_{t}^{F}$}

We used the test results of the $40 \%$ ONP fibers composite with 0 to $8 \%$ of MAPP to study the influence of the MAPP on the micromechanics. To compute the interfacial shear strength, the orientation factor and the intrinsic fiber tensile strength we used Kelly- Tyson equations and he Bowyer-Bader methodology [25, 34]. The theoretical intrinsic Young's modulus of the ONP fibers was computed using Hirsch model [32]. It was observed that the addition of MAPP had little influence on the orientation factor. Figure 5 shows the interfacial shear strength, and the intrinsic strength of the ONP fibers when different percentages of MAPP were added. The intrinsic strength of the ONP fibers and the interfacial shear strength showed similar behaviors to that of the composite tensile strength. The fiber showed its capabilities as reinforcement in parallel with the increases of the interfacial shear strength. A good interface prevented fiber matrix slippage.

\section{Figure 5}

\subsection{Contribution of the matrix and the subcritical and supercritical fibers to the composite strength}


Eq. 1. could be simplified to $\sigma_{t}^{C}=\chi_{1}(X+Y)+Z$ where $X, Y$, and $Z$ are the contribution of the subcritical fibers, supercritical fibers and the matrix to the composite strength $\left(\sigma_{t}^{C}\right)$. Values for $X, Y$ and $Z$ were calculated from Eqs. 2, 3 and 4 respectively. To estimate the final contribution to the composite $X$ and $Y$ must be multiplied by $\chi_{1}$.

$$
\begin{aligned}
& X=\sum_{i}^{l_{i}^{F}<l_{c}^{F}} \frac{\tau \cdot l_{i}^{F} \cdot V_{i}^{F}}{d^{F}} \\
& Y=\sum_{j}^{l_{j}^{F}>l_{c}^{F}} \sigma_{t}^{F} \cdot V_{j}^{F}\left(1-\frac{\sigma_{t}^{F} \cdot d^{F}}{4 \cdot \tau \cdot l_{j}^{F}}\right) \\
& Z=\left(1-V^{F}\right) \cdot \sigma_{t}^{m *}
\end{aligned}
$$

Figure 6 shows that the contribution of the subcritical fibers remains minimum, but not negligible for the composites with bigger amount of reinforcement. Thus for the case of 50 $w t \%$ it represent the $16 \%$ of the total and approximately half of the contribution of the polymeric matrix. In the $40 \mathrm{wt} \%$ case the contribution represents an $13.1 \%$ contribution and more or less $1 / 3$ of the contribution of the matrix. The contribution of subcritical fibers in the cases of $30 \%$ and $20 \mathrm{wt} \%$ composites was $10.3 \%$ and $9 \%$ respectively. In all the cases it is clear the contribution of supercritical fibers, representing respectively the $33.9 \%, 46 \%$, $54.2 \%$ and $59.8 \%$. Taking in account the cumulative contribution of the fibers $(X+Y)$ the amount increases respectively to $43.3 \%, 56.4 \%, 67.3 \%$ and $75.7 \%$. This behavior could be due the increase in the relative presence of MAPP in respect to PP and consequently the probability of creation of hydrogen bonds in the interface.

\section{Figure 6}




\section{Conclusions}

The old newspaper fibers, once coupled, showed its potential as reinforcement for polypropylene composites when a 2 to $6 w t \%$ of MAPP was added.

The Bowyer-Bader methodology, as analytical method to solve Kelly-Tyson equation, showed its usefulness when applied on the mechanical properties of ONP fiber reinforced polypropylene composites.

The equivalent mean intrinsic tensile strength of the ONP fibers at failure was defined and found to be $514.3 \pm 34.7 \mathrm{MPa}$.

The mean orientation factor for the ONP/PP/MAPP composites was found to be $0.346 \pm, 0.02$ representing a mean orientation angle of $39.9^{\circ}$.

The mean interfacial shear strength of the ONP/PP/MAPP composites was found to be $14.57 \pm 0.63 \mathrm{MPa}$.

The improvements in the interfacial shear strength where directly related with the efficiency of the ONP fibers as reinforcement.

The contribution of the supercritical fibers to the tensile strength of the composite increased quickly with the fiber content. At the same time the contribution of the matrix descended and the contribution of the subcritical fibers increased slowly.

\section{References}

[1] Osman H, Ismail H, Mariatti M. Comparison of Reinforcing Efficiency between Recycled Newspaper (RNP)/Carbon Black (CB) and Recycled Newspaper (RNP)/Silica Hybrid Filled Polypropylene (PP)/Natural Rubber (NR) Composites. Journal of Reinforced Plastics and Composites. 2010;29(1):60-75. 
[2] Rowell RM, Sanadi AR, Caulfield DF, Jacobson RE. Utilization of Natural Fibres in Plastic Composites: Problems and Opportunities. In: Leao AL, Carvalho FX, Frollini E, editors. Lignocellulosic-Plastics Composites. Sao Paulo (Brazil): Universidade de Sao Paulo, Universidade Estadual Paulista; 1997.

[3] Flandez J, González I, Resplandis JB, El Mansouri N-E, Vilaseca F, Mutjé P. Management of corn stalk waste as reinforcement for polypropylene injection moulded composites. BioResources. 2012;2(7):1836-49.

[4] Franco-Marques E, Mendez JA, Pelach MA, Vilaseca F, Bayer J, Mutje P. Influence of coupling agents in the preparation of polypropylene composites reinforced with recycled fibers. Chemical Engineering Journal. 2011;166(3):1170-8.

[5] Girones J, Pimenta MTB, Vilaseca F, Carvalho AJF, Mutje P, Curvelo AAS. Blocked diisocyanates as reactive coupling agents: Application to pine fiber-polypropylene composites. Carbohydrate Polymers. 2008;74(1):10613.

[6] Vilaseca F, Mendez JA, Lopez JP, Vallejos ME, Barbera L, Pelach MA, et al. Recovered and recycled Kraft fibers as reinforcement of PP composites. Chemical Engineering Journal. 2008;138(1-3):586-95.

[7] Mendez JA, Vilaseca F, Pelach MA, Lopez JP, Barbera L, Turon X, et al. Evaluation of the reinforcing effect of ground wood pulp in the preparation of polypropylene-based composites coupled with maleic anhydride grafted polypropylene. J Appl Polym Sci. 2007;105(6):3588-96.

[8] Girones J, Mendez JA, Boufi S, Vilaseca F, Mutje P. Effect of silane coupling agents on the properties of pine fibers/polypropylene composites. J Appl Polym Sci. 2007;103(6):3706-17.

[9] Lopez JP, Mendez JA, Espinach FX, Julian F, Mutje P, Vilaseca F. Tensile Strength characteristics of Polypropylene composites reinforced with Stone Groundwood fibers from Softwood. BioResources. 2012;7(3):3188-200. [10] Girones J, Lopez JP, Mutje P, Carvalho AJF, Curvelo AAS, Vilaseca F. Natural fiber-reinforced thermoplastic starch composites obtained by melt processing. Composites Science and Technology. 2012;72(7):858-63.

[11] Girones J, Lopez JP, Vilaseca F, Bayer R J, Herrera-Franco PJ, Mutje P. Biocomposites from Musa textilis and polypropylene: Evaluation of flexural properties and impact strength. Composites Science and Technology. 2011;71(2):122-8.

[12] Cañigueral N, Vilaseca F, Méndez JA, López JP, Barberà L, Puig J, et al. Behavior of biocomposite materials from flax strands and starch-based biopolymer. Chemical Engineering Science. 2009;64(11):2651-8.

[13] Pimenta MTB, Carvalho AJF, Vilaseca F, Girones J, Lopez JP, Mutje P, et al. Soda-Treated Sisal/Polypropylene Composites. Journal of Polymers and the Environment. 2008;16(1):35-9. 
[14] Mutje P, Lopez A, Vallejos ME, Lopez JP, Vilaseca F. Full exploitation of Cannabis sativa as reinforcement/filler of thermoplastic composite materials. Composites Part a-Applied Science and Manufacturing. 2007;38(2):369-77.

[15] Mutje P, Vallejos ME, Girones J, Vilaseca F, Lopez A, Lopez JP, et al. Effect of maleated polypropylene as coupling agent for polypropylene composites reinforced with hemp strands. J Appl Polym Sci. 2006;102(1):833-40.

[16] Sain M, Suhara P, Law S, Bouilloux A. Interface modification and mechanical properties of natural fiber-polyolefin composite products. Journal of Reinforced Plastics and Composites. 2005;24(2):121-30.

[17] Sain MM, Imbert C, Kokta BV. Composites of surface-treated wood fiber and recycled polypropylene. Angewandte Makromolekulare Chemie. 1993;210:33-46.

[18] Baroulaki I, Karakasi O, Pappa G, Tarantili PA, Economides D, Magoulas K. Preparation and study of plastic compounds containing polyolefins and post used newspaper fibers. Composites Part a-Applied Science and Manufacturing. 2006;37(10):1613-25.

[19] Li X, Tabil LG, Panigrahi S. Chemical treatments of natural fiber for use in natural fiber-reinforced composites: A review. Journal of Polymers and the Environment. 2007;15(1):25-33.

[20] Beg MDH, Pickering KL. Mechanical performance of Kraft fibre reinforced polypropylene composites: Influence of fibre length, fibre beating and hygrothermal ageing. Composites Part a-Applied Science and Manufacturing. 2008;39(11):1748-55.

[21] Zabhizadeh SM, Ebrahimi G, Enayati AA. Effect of Compatibilizer on Mechanical, Morphological, and Thermal Properties of Chemimechanical Pulp-reinforced PP Composites. Journal of Thermoplastic Composite Materials. 2011;24(2):221-31.

[22] Corbiere-Nicollier T, Gfeller-Laban B, Lundquist L, Leterrier Y, Manson JAE, Jolliet 0 . Life cycle assessment of biofibres replacing glass fibres as reinforcement in plastics. Resources Conservation and Recycling. 2001;33(4):267-87.

[23] Sanadi AR, Young RA, Clemons C, Rowell RM. Recycled newspaper fibers as reinforcing fillers in thermoplastic: 1 analysis of tensile and impact properties in polypropylene Journal of Reinforced Plastics and Composites. 1994;13(1):54-67.

[24] Yadav P, Nema A, Varghese S, Nema SK. Newspaper-reinforced plastic composite laminates: Mechanical and water uptake characteristics. Polymer Engineering and Science. 1999;39(8):1550-7. 
[25] Kelly A, Tyson W. Tensile porperties of fibre-reinforced metals copper/tungsten and copper/molybdenum. Journal of the Mechanics and Physics of Solids. 1965;13(6):329-38.

[26] Vallejos ME, Espinach FX, Julian F, Torres L, Vilaseca F, Mutje P. Micromechanics of hemp strands in polypropylene composites. Composites Science and Technology. 2012:on revision.

[27] Li Y, Pickering KL, Farrell RL. Determination of interfacial shear strength of white rot fungi treated hemp fibre reinforced polypropylene. Composites Science and Technology. 2009;69(7-8):1165-71.

[28] Lopez JP, Mendez JA, El Mansouri NE, Mutje P, Vilaseca F. Mean intrinsic tensile properties of stone groundwood fibers from softwood. BioResources. 2011;6(4):5037-49.

[29] Rodriguez M, Rodriguez A, Bayer R J, Vilaseca F, Girones J, Mutje P. Determination of corn stalk fibers' strength through modeling of the mechanical properties of its composites. BioResources. 2010;5(4):2535-46. [30] Vilaseca F, Valadez-Gonzalez A, Herrera-Franco PJ, Pelach MA, Lopez JP, Mutje P. Biocomposites from abaca strands and polypropylene. Part I: Evaluation of the tensile properties. Bioresource Technology. 2010;101(1):387-95.

[31] El Mansouri N-E, Espinach FX, Julian F, Verdaguer N, Torres L, Llop MF, et al. Research on the suitability of organosolv semi-chemical triticale fibers as reinforcement for recycled HDPE composites. BioResources. 2012;7(4):5032-47.

[32] Hirsch T. Modulus of elasticity of concrete affected by elastic moduli of cement paste matrix and aggregate. Journal of American Concrete Institute. 1962;59(3):427-51.

[33] Thomason JL. Interfacial strength in thermoplastic composites - at last an industry friendly measurement method? Composites Part a-Applied Science and Manufacturing. 2002;33(10):1283-8.

[34] Bowyer WH, Bader HG. On the reinforcement of thermoplastics by imperfectly aligned discontinuous fibres. J Mater Sci. 1972;7(11):1315-2.

[35] Colom X, Carrasco F, Pages P, Canavate J. Effects of different treatments on the interface of HDPE/lignocellulosic fiber composites. Composites Science and Technology. 2003;63(2):161-9.

[36] de Carvalho FP, Felisberti MI, Oviedo MAS, Vargas MD, Farah M, Ferreira MPF. Rice Husk/Poly(propylene-co-ethylene) Composites: Effect of Different Coupling Agents on Mechanical, Thermal, and Morphological Properties. J Appl Polym Sci. 2012;123(6):3337-44.

[37] Osman H, Ismail H, Mustapha M. Effects of Maleic Anhydride Polypropylene on Tensile, Water Absorption, and Morphological Properties of Recycled Newspaper Filled Polypropylene/Natural Rubber Composites. Journal of Composite Materials. 2010;44(12):1477-91. 
[38] Vallejos ME, Canigueral N, Mendez JA, Vilaseca F, Corrales F, Lopez A, et al. Benefit from hemp straw as filler/reinforcement for composite materials. Afinidad. 2006;63(525):354-61.

[39] Bourmaud A, Baley C. Investigations on the recycling of hemp and sisal fibre reinforced polypropylene composites. Polymer Degradation and Stability. 2007;92(6):1034-45.

[40] Karmaker AC, Youngquist JA. Injection molding of polypropylene reinforced with short jute fibers. J Appl Polym Sci. 1996;62(8):1147-51.

[41] Mittal RK, Gupta VB, Sharma P. The effect of fibre orientation on the interfacial shear stress in short fibre - reinforced polypropylene. J Mater Sci. 1987(22):1949-55.

[42] Pegoretti A, DellaVolpe C, Detassis M, Migliaresi C, Wagner HD. Thermomechanical behaviour of interfacial region in carbon fibre/epoxy composites. Composites Part a-Applied Science and Manufacturing. 1996;27(11):1067-74. 
Table 1. Tensile mechanical properties of composite reinforced with ONP with 6 wt\% of MAPP. Inside the parenthesis is the standard deviation.

\begin{tabular}{|c|c|c|c|c|}
\hline \multirow{2}{*}{$\begin{array}{c}\text { Reinforcement } \\
(\mathbf{w t} \%)\end{array}$} & \multirow{2}{*}{$\begin{array}{c}\text { Volume } \\
\text { Fraction }\end{array}$} & \multicolumn{3}{|c|}{ Old newspaper } \\
\cline { 3 - 5 } & $\mathbf{V}^{\mathrm{F}}$ & \multicolumn{3}{|c|}{ With 6\% MAPP } \\
\cline { 3 - 5 } & & $\boldsymbol{\sigma}_{\mathrm{t}}^{\mathrm{C}}(\mathbf{M P a})$ & $\mathbf{E}_{\mathrm{t}}^{\mathrm{C}}(\mathbf{G P a})$ & $\varepsilon_{\mathrm{t}}^{\mathrm{C}}(\%)$ \\
\hline 0 & 0 & $27.6[0.5]$ & $1.5[0.1]$ & $9.3[0.2]$ \\
\hline 20 & 0.148 & $38.7[1.1]$ & $2.8[0.2]$ & $4.1[0.5]$ \\
\hline 30 & 0.222 & $43.9[1.3]$ & $3.8[0.1]$ & $3.6[0.3]$ \\
\hline 40 & 0.296 & $45.2[1.2]$ & $4.2[0.2]$ & $2.5[0.2]$ \\
\hline 50 & 0.370 & $49.6[1.3]$ & $5.3[0.2]$ & $2.2[0.1]$ \\
\hline
\end{tabular}


Table 2. 20 to 50\% ONP fiber Composite with a 6wt\% MAPP properties. Stress-Strain input data and parameters

\begin{tabular}{|c|c|c|c|c|c|c|c|}
\hline $\begin{array}{c}\text { Reinforcement } \\
\text { content (\%) }\end{array}$ & $\begin{array}{c}\text { Average } \\
\text { length } \\
(\mu \mathrm{m})\end{array}$ & $\begin{array}{c}\text { Weighted } \\
\text { average } \\
\text { length } \\
(\mu \mathrm{m}) \\
\end{array}$ & $\begin{array}{c}\text { Average } \\
\text { diameter } \\
(\mu \mathrm{m})\end{array}$ & $\begin{array}{c}\text { Composite } \\
\text { strength } \\
\text { (Mpa) }\end{array}$ & $\begin{array}{c}\text { Composite } \\
\text { modulus } \\
\text { (Gpa) }\end{array}$ & $\begin{array}{c}\text { Fiber } \\
\text { modulus } \\
(\mathrm{Gpa})\end{array}$ & $\begin{array}{c}\text { Elongation } \\
\text { at break } \\
(\%)\end{array}$ \\
\hline $20 \%$ & 237 & 1094 & 21.6 & 38.7 & 2.87 & 21.2 & 4.1 \\
\hline $30 \%$ & 265 & 664 & 21.6 & 43.9 & 3.83 & 21.2 & 3.6 \\
\hline $40 \%$ & 260 & 526 & 21.6 & 45.2 & 4.18 & 21.2 & 2.5 \\
\hline $50 \%$ & 198 & 416 & 21.6 & 49.6 & 5.31 & 21.2 & 2.2 \\
\hline $\begin{array}{c}\text { Reinforcement } \\
\text { content (\%) }\end{array}$ & \begin{tabular}{|c} 
Strain level \\
1 analyzed \\
$(\%)$
\end{tabular} & $\begin{array}{c}\text { Composite } \\
\text { stress at } \\
\text { strain level } \\
1(\mathrm{MPa}) \\
\end{array}$ & $\begin{array}{c}\text { Strain level } \\
2 \text { analyzed } \\
(\%)\end{array}$ & $\begin{array}{c}\text { Composite } \\
\text { stress at } \\
\text { strain level } \\
2(\mathrm{MPa})\end{array}$ & $\begin{array}{c}\text { Matrix } \\
\text { stress at } \\
\text { strain level } \\
1(\mathrm{MPa}) \\
\end{array}$ & $\begin{array}{c}\text { Matrix } \\
\text { stress at } \\
\text { strain level } \\
2(\mathrm{MPa}) \\
\end{array}$ & $\begin{array}{c}\text { Matrix } \\
\text { stress at } \\
\text { break } \\
\text { (Mpa) }\end{array}$ \\
\hline $20 \%$ & 1.37 & 24.66 & 2.73 & 37.22 & 15.1 & 22.3 & 25.6 \\
\hline $30 \%$ & 1.2 & 26.26 & 2.4 & 40.11 & 13.68 & 21.01 & 24.7 \\
\hline $40 \%$ & 0.84 & 22.06 & 1.67 & 36.43 & 10.33 & 17.12 & 21.4 \\
\hline $50 \%$ & 0.73 & 22.95 & 1.47 & 38.68 & 9.3 & 15.75 & 20.1 \\
\hline
\end{tabular}


Table 3. 20 to 50\% ONP fiber Composite with a 6wt $\%$ MAPP output data

\begin{tabular}{|c|c|c|c|c|}
\hline $\begin{array}{c}\text { Reinforcement } \\
\text { content (\%) }\end{array}$ & $\begin{array}{c}\text { Interface } \\
\text { Shear } \\
\text { Otrength } \\
(\mathrm{Mpa}) \\
\tau\end{array}$ & $\begin{array}{c}\text { Fiber's } \\
\text { tensile } \\
\text { strength } \\
(\mathrm{Mpa}) \\
\boldsymbol{\chi}_{1}^{\mathrm{F}}\end{array}$ & $\begin{array}{c}\text { Critical } \\
\text { length } \\
(\mu \mathrm{m}) \\
\mathrm{I}_{\mathrm{c}}^{\mathrm{F}}\end{array}$ \\
\hline $\mathbf{2 0 \%}$ & 0.373 & 14.5 & 500 & 372 \\
\hline $\mathbf{3 0 \%}$ & 0.356 & 14.45 & 554 & 413 \\
\hline $\mathbf{4 0 \%}$ & 0.327 & 15.42 & 529 & 369 \\
\hline $\mathbf{5 0 \%}$ & 0.329 & 13.91 & 474 & 366 \\
\hline
\end{tabular}




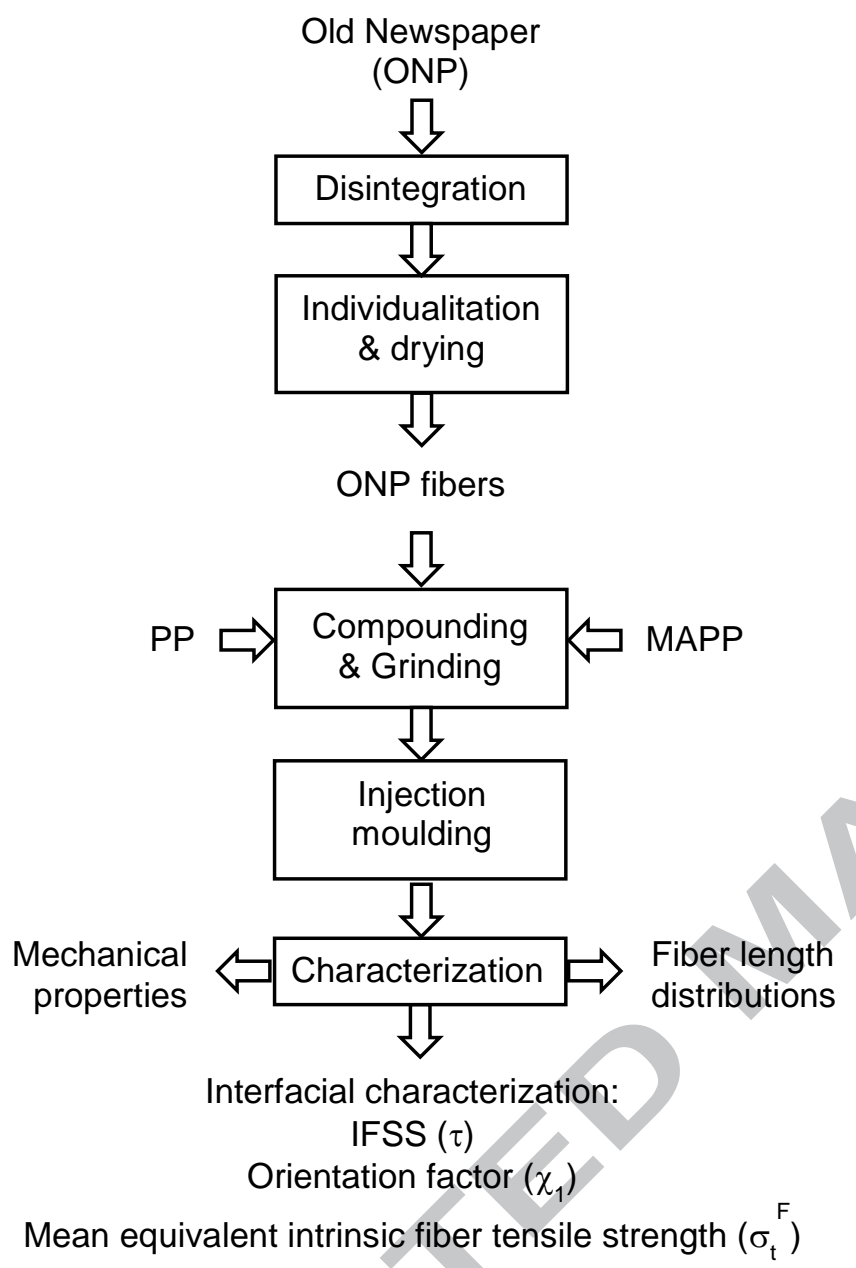

Figure 1: Flow chart of the experimental procedure 


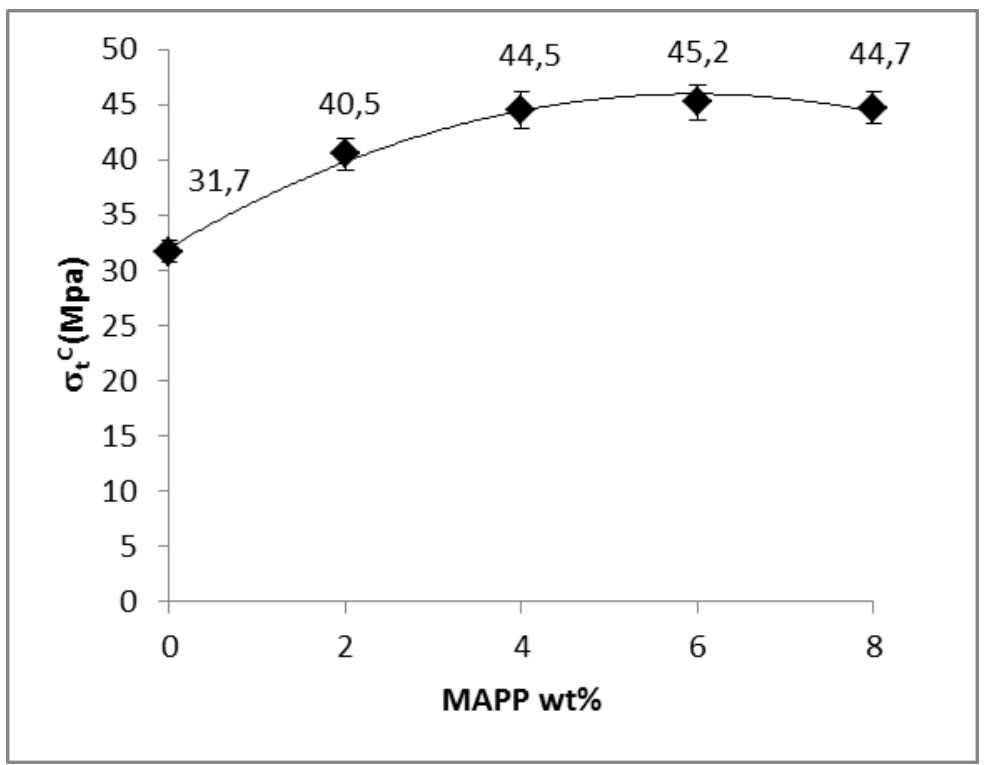

Figure 2: Evolution of the Composite tensile strength $\left(\sigma_{t}{ }^{C}\right)$ of the $40 w t \%$ ONP fibers composite materials against the MAPP wt\%. 


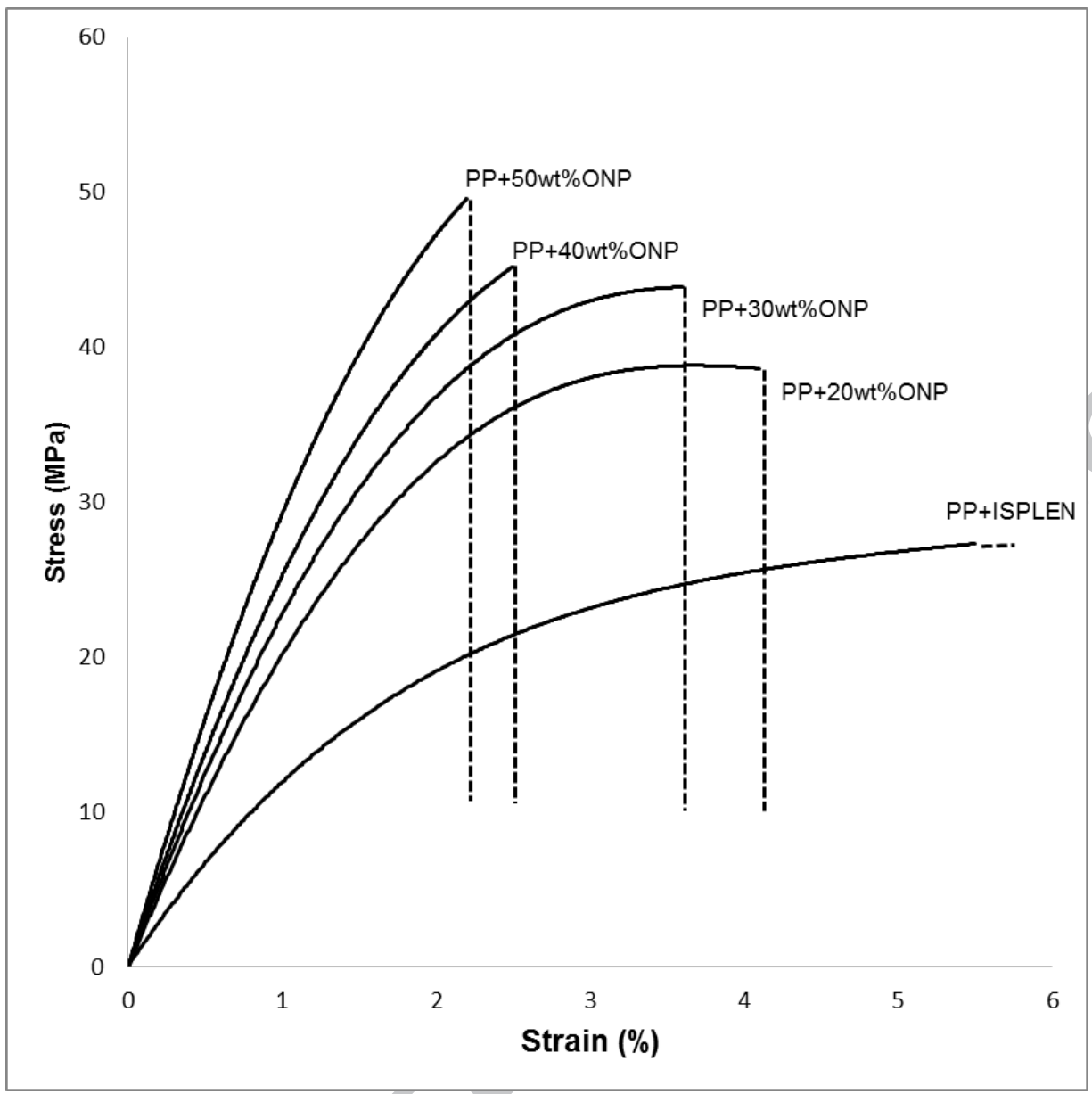

Figure 3: Stress-Strain curve for the tested PP-MAPP-ONP composites 

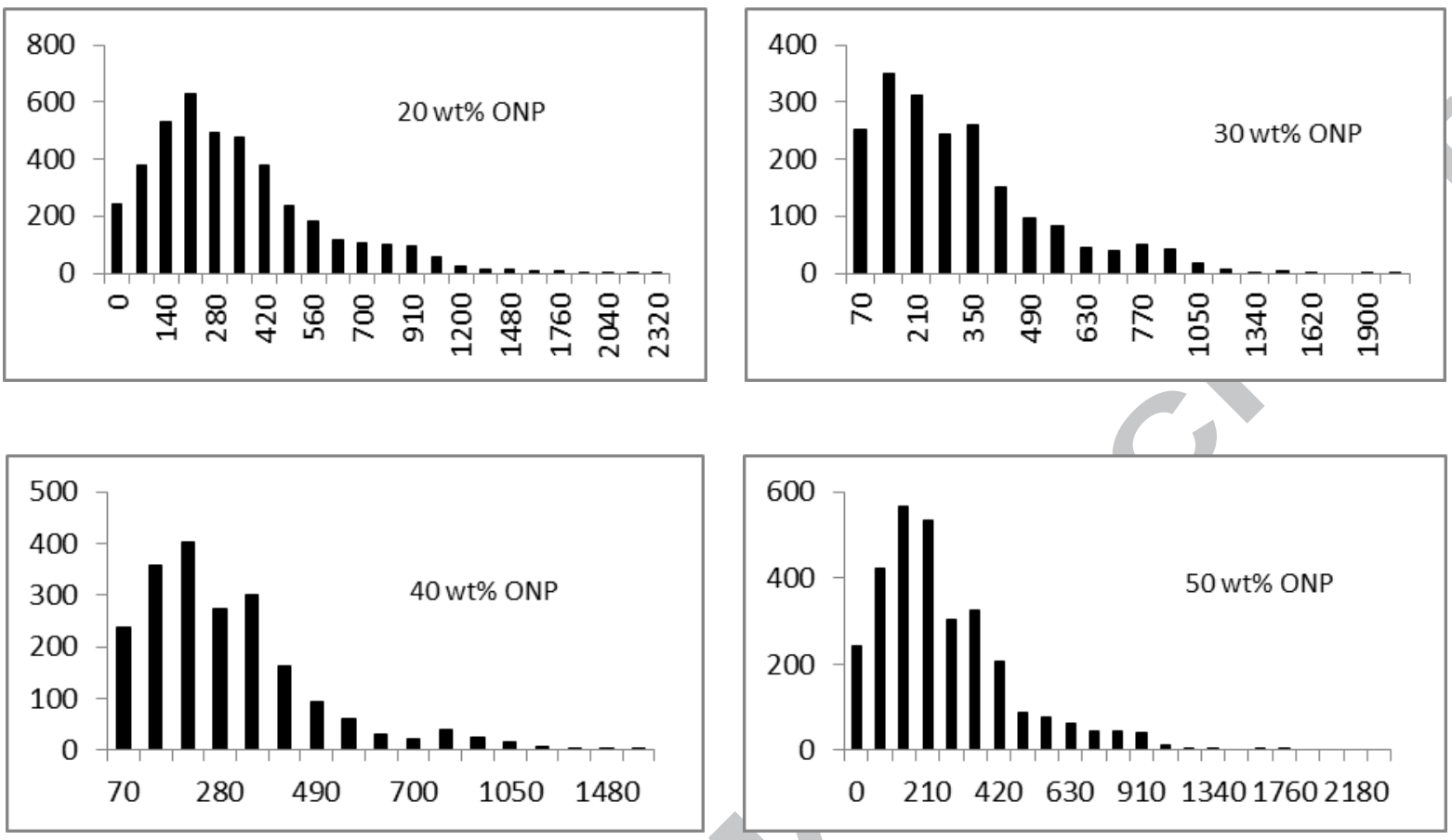

Figure 4: Fiber length distribution for the tested PP-MAPP-ONP composites. 


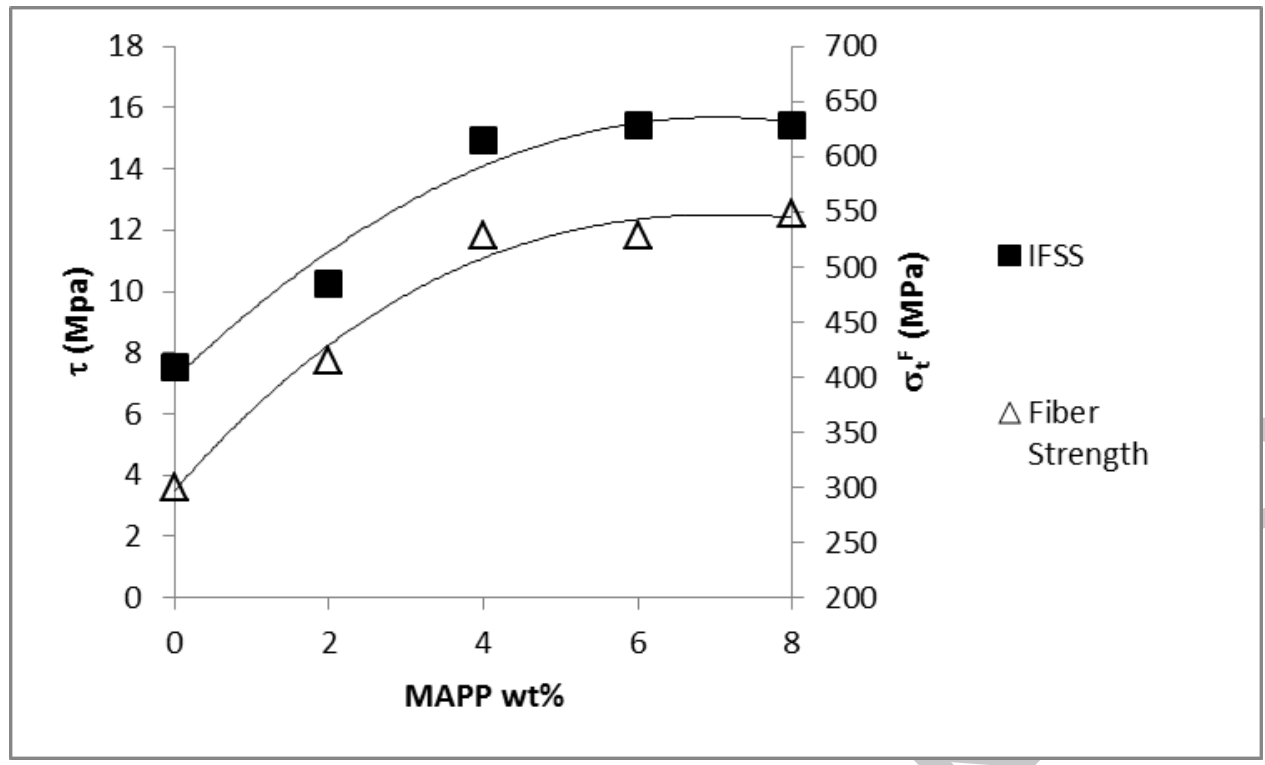

Figure 5: Evolution of the Composite interfacial shear strength $(\tau)$ and the intrinsic strength of the ONP fibers $\left(\sigma_{t}{ }^{F}\right)$ of the $40 w t \%$ ONP fibers composite materials against the MAPP wt $\%$. 


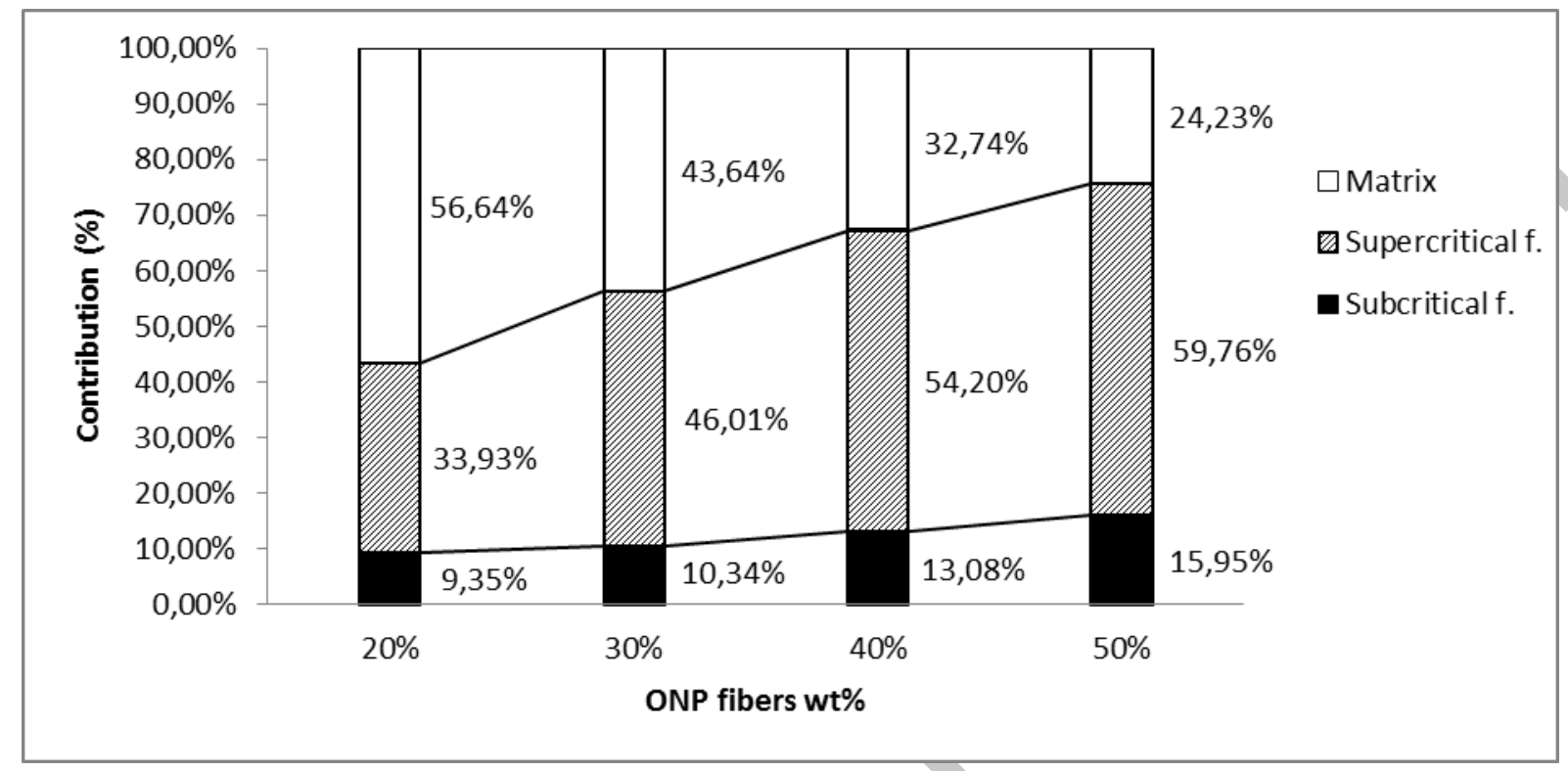

Figure 6: Contribution of the subcritical, supercritical and matrix to the tensile strength of the composite materials. 